\title{
Effect of Rheumatoid Arthritis on the Masticatory Muscles' Thickness, Bite Force, Mandibular Mobility and Quality of Life of Adult Women
}

\author{
Laíse Angélica Mendes Rodrigues ${ }^{1}$, Selma Siéssere ${ }^{1}$, Graziela De Luca Canto², Oswaldo Luiz Stamato \\ Taube ${ }^{1}$, Edson Donizetti Verri ${ }^{1}$, Leonardo Giovannetti Palinkas ${ }^{1}$, Isabela Hallak Regalo ${ }^{1}$, Simone \\ Cecilio Hallak Regalo ${ }^{1 *}$ and Marcelo Palinkas ${ }^{1}$
}

\begin{abstract}
${ }^{1}$ Department of Morphology, Physiology and Basic Pathology, Ribeirão Preto School of Dentistry, University of São Paulo, São Paulo, Brazil

${ }^{2}$ Department of Dentistry, Federal University of Santa Catarina, Florianopolis, Brazil; Department of Dentistry, University of Alberta, Edmonton, Canada
\end{abstract}

*Corresponding author: Simone Cecilio Hallak Regalo, Department of Morphology, Physiology and Basic Pathology, Ribeirão Preto School of Dentistry, University of São Paulo, São Paulo, Brazil, Tel: +55-1-3315-0281, E-mail: simone@forp.usp.br

\begin{abstract}
Objective: Analyze the stomatognathic system of adult women with rheumatoid arthritis through the masseter and temporalis muscles' thickness, maximum molar bite force, mandibular mobility and repercussion of the oral conditions in the quality of life.
\end{abstract}

Methods: Twenty-eight women were divided into two groups: with rheumatoid arthritis $(n=14$, mean age $52.2 \pm 3.0$ years, RAG) and without rheumatoid arthritis ( $n=14$, mean age 49.4 \pm 2.4 years, CG). Masseter and temporalis muscles' thickness was measured at rest and maximum voluntary contraction by ultrasound. Maximum molar bite force (right and left) was captured by digital dynamometer. Mandibular mobility in the maximum mouth opening, right lateral excursion, left lateral excursion and protrusion was measured by digital caliper. Repercussion of oral conditions on quality of life was verified by the Oral Health Impact Profile questionnaire (OHIP-14).

Results: There were statistically significant differences in maximum molar bite force right side of the dental arch, $(P$ $=0.03$ ) and repercussion of oral conditions on quality of life by the sum of OHIP-14 $(P=0.00)$ between RAG and CG.

Conclusion: Women with rheumatoid arthritis showed decrease in maximum molar bite force and negative impact on the repercussion of oral conditions on quality of life. However, there was no significant statistical difference for masticatory muscles' thickness and mandibular mobility.

\section{Keywords}

Rheumatoid arthritis, Masticatory muscles, Ultrasound, Bite force, Mandibular mobility, Quality of life

\begin{abstract}
Abbreviations
RAG: Rheumatoid Arthritis Group; CG: Without Rheumatoid Arthritis Group; OHIP-14: Oral Health Impact Profile Questionnaire
\end{abstract}

\section{Introduction}

Chronic degenerative diseases modify the function of the human organism, altering the quality of life [1,2]. These diseases include rheumatoid arthritis, which is considered progressive, autoimmune, chronic and inflammatory systemic disease [3,4]. Rheumatoid arthritis is usually identified by swelling, stiffness and destruction of synovial cartilages, and can promote joint deformities and muscle fatigue [5-7].

The individual affected by rheumatoid arthritis may become unable to perform daily life activities because of joint damage progression, altering daily habits such as locomotion, arm support, oral hygiene, food chewing and mandibular excursion movements $[8,9]$.

The incidence of rheumatoid arthritis in the population increases over time, being the age group from 40 to 60 years of age more affected and reaching more the female gender $[10,11]$.

In the USA, the disease affects 1.28 to 1.36 million patients [12] and it is estimated that by 2020, 59.4 mil-

Citation: Rodrigues LAM, Siéssere S, Canto GDL, Taube OLS, Verri ED, et al. (2017) Effect of Rheumatoid Arthritis on the Masticatory Muscles' Thickness, Bite Force, Mandibular Mobility and Quality of Life of Adult Women. Int J Oral Dent Health 3:047. doi.org/10.23937/2469-5734/1510047 Received: June 20, 2017: Accepted: August 30, 2017: Published: September 01, 2017 Copyright: (C) 2017 Rodrigues LAM, et al. This is an open-access article distributed under the terms of the Creative Commons Attribution License, which permits unrestricted use, distribution, and reproduction in any medium, provided the original author and source are credited. 
lion north American adults will develop rheumatoid arthritis [13]. In Brazil, rheumatoid arthritis affects 1.3 million adult individuals [5].

The stomatognathic system which is a functional anatomical unit integrating the human organism, composed of interdependent organs and tissues [14]. Rheumatoid arthritis may result functional limitation in the temporomandibular joint and consequently of the stomatognathic system [15-17].

Given the prevalence of rheumatoid arthritis in the world population and the disease's capacity to cause progressive and limiting damage in the synovial joints, such as temporomandibular joint, becomes research relevant that evaluate the morphology and function of the stomatognathic system, in addition to the impact on quality of life in patients with rheumatoid arthritis, with the purpose of demonstrating topics that were not studied by the scientific community.

Therefore, the aim of this study was to analyze the stomatognathic system of adult women with rheumatoid arthritis, observing the masticatory muscles' thickness, maximum molar bite force, mandibular mobility and repercussion of the buccal conditions in the quality of life.

\section{Material and Methods}

\section{Study design}

This study was conducted in reference centers specialized in the treatment of chronic degenerative diseases located in the cities of Ribeirao Preto, Batatais and Bebedouro in the State of São Paulo, Brazil. The approval of the ethics committee was obtained by the Dentistry Faculty of Ribeirão Preto of the University of São Paulo (process n. 43010515.8.0000.5419), in compliance with Resolution 466/12 of the Brazilian National Health Council. Free and informed consent was informed in writing and obtained from each research participant.

\section{Study population}

This study evaluated one hundred and two women (aged between 40 and 60) with rheumatoid arthritis, diagnosed by rheumatologists, based on the association of clinical signs, symptoms, laboratory findings and radiographic images [5]. Thirty-five did not agree to participate in the study, therefore, sixty-seven women with complete dentition, without the presence of wisdom teeth, normal occlusion and without symptoms temporomandibular dysfunction (Research Diagnostic Criteria for Temporomandibular Disorders (RDC/TMD) - Axis I) [18] who were submitted to anamnesis and clinical evaluation, performed by the same dentist. According to pre-established criteria in this study, by clinical evaluation and anamnesis, women with bruxism $(n=8)$, bruxism in wakefulness $(n=5)$, obstructive sleep apnea syndrome $(n=6)$, mandibular tori $(n=3)$, neurological or psychiatric disorders $(n=4)$, physical or mental illness $(n=6)$, who were under physiotherapeutic treatment $(n=5)$ and in the use of medications that may interfere with skeletal muscle activity $(n=16)$, were excluded from the sample.

Thus, it was possible to select 14 women (mean age $52.2 \pm 3.0$ years and BMI $31.1 \pm 1.2 \mathrm{~kg} / \mathrm{m}^{2}$ ) with rheumatoid arthritis in the early stage of the disease and without therapeutic control for over a year, presenting sensitivity to digital palpation in the right and left pre-auricular region to compose the group with Rheumatoid Arthritis (RAG). The Control Group (CG) was composed of 14 women (mean age $49.4 \pm 2.4$ years and BMI $27.5 \pm 1.1 \mathrm{~kg} / \mathrm{m}^{2}$ ) without rheumatoid arthritis. The groups were matched oneto-one, using gender and Body Mass Index (BMI), totalizing 28 women in this study. The BMI was calculated using kilograms and meters: $\mathrm{BMI}=$ weight in kilograms/(height in meters) $\times$ (height in meters). Weight was measured with balanced beam. The patient was standing in the center of platform, with $10 \mathrm{~cm}$ gap between the heels. Height was measured without shoes, heavy outer garments and hair ornaments. The back of the head, shoulders, shoulder blades, touched the portable stadiometer.

\section{Sample size}

Probabilistic sample was calculated in this study, considering the sample calculation the finite population of 204 million Brazil's population in 2014, occurrence of rheumatoid arthritis in $0.88 \%$ of the population, margin of error of $5 \%$ and $95 \%$ confidence interval. From there, it was estimated sample of 14 individuals.

\section{Muscle thickness analysis}

A single trained professional measured the thickness of the masseter and temporalis muscles directly on the image at the time of its acquisition, to the nearest 0.1 $\mathrm{mm}$, using the NanoMaxx ultrasound device (SonoSite, Bothell, WA, USA) with a linear transducer of $10 \mathrm{MHz}$ positioned transversely to the direction of the muscle fibers, in the belly of the masseter and temporal muscles [19]. The participants remained comfortably seated, leaning, standing erect, without fixation of the head, the soles of the feet resting on the ground and the palms of the hands resting on the thighs. The average of three measurements made on three ultrasound images obtained from each muscle in the condition of mandibular rest and dental clenching in maximum voluntary contraction, with interval of two minutes between each measurement [20].

\section{Maximum molar bite force analysis}

The maximum molar bite force was recorded in Newton $(\mathrm{N})$, with the digital dynamometer, IDDK (Kratos, Equipamentos Industriais Ltda., Cotia, São Paulo, Brazil), adapted for oral conditions, to not produce exaggerated condylar displacement nor muscular distention. 
The fork strength of the device was cleaned with alcohol, protected with disposable latex finger cots (Wariper, São Paulo, Brazil) for biosafety and positioned in the region of the first permanent molars $[19,21]$. The "peaks" of three measurements of bite force on each side of the dental arch were recorded, with maximal effort and rest of two minutes between the records, alternating the right and left sides [22]. The highest value of the three-maximum molar bite force registers was used.

\section{Mandibular mobility analysis}

The mandibular mobility was evaluated by average of three measurements performed with Mitutoyo ${ }^{\circledR}$ digital caliper (Suzano, São Paulo, Brazil) of maximum mouth opening, right lateral excursion, left lateral excursion and protrusion. The patients were previously advised on the examination that would be performed, on the movements that they should perform and were instructed to breathe slowly, to remain relaxed. The digital caliper was positioned in the incisal and mesial region of the right upper central incisor and the incisal and mesial region of the lower right central incisor. The reference standards were the dental middle lines, correcting the pre-existing deviations [23].

\section{Analysis of oral health conditions in quality of life}

The OHIP-14 (Oral Health Impact Profile) questionnaire was used to evaluate patient's perception of the impact of oral health conditions on their well-being during the last year. The questionnaire consists of 14 questions that were grouped into seven situations: (1) Functional limitation, (2) Physical pain, (3) Psychological discomfort, (4) Physical limitation, (5) Psychological limitation, (6) Social limitation, and (7) Disability. The responses were recorded on a Likert scale with values from zero to four, in which the lowest value on the scale characterized the quality of life [24-26].

\section{Statistical analysis}

The data were analyzed using the Statistical Package for Social Sciences (SPSS version 21.0, IBM ${ }^{\circ}$, USA). Descriptive analysis (means and standard error) and normality test were performed for each variable, which were then compared by student's t-test for independent samples, with significance level of $5 \%$ and $95 \%$ confidence interval.

\section{Results}

The average masseter and temporalis muscles' thickness of the RAG were compared to the CG and no significant differences were observed $(P \geq 0.05)$ according to data from Table 1.

Table 2 shows the maximum right and left molar bite force of RAG compared to CG. There was a reduction in maximum molar bite force (right and left) in RAG compared to $C G$ with significant statistical difference for the right side $(P=0.03)$.
Table 1: Average, standard error $( \pm)$ and test statistic "t" (P $\leq 0.05)$ of muscle thickness $(\mathrm{cm})$ of the Rheumatoid Arthritis (RAG) and Control Groups (CG), in the Right Masseter (RM), Left Masseter (LM), Right Temporal (RT) and Left Temporal (LT) muscles in mandibular rest and Maximum Voluntary Contraction (MVC).

\begin{tabular}{|c|l|l|l|}
\hline Muscular thickness & RAG & CG & P-value \\
\hline Rest & & & \\
\hline RM & $0.75 \pm 0.04$ & $0.75 \pm 0.02$ & 0.90 \\
\hline LM & $0.77 \pm 0.03$ & $0.79 \pm 0.03$ & 0.59 \\
\hline RT & $0.37 \pm 0.03$ & $0.40 \pm 0.03$ & 0.49 \\
\hline LT & $0.38 \pm 0.02$ & $0.42 \pm 0.03$ & 0.32 \\
\hline MVC & & & \\
\hline RM & $1.02 \pm 0.06$ & $1.04 \pm 0.05$ & 0.86 \\
\hline LM & $1.02 \pm 0.05$ & $1.09 \pm 0.05$ & 0.34 \\
\hline RT & $0.44 \pm 0.04$ & $0.50 \pm 0.04$ & 0.33 \\
\hline LT & $0.44 \pm 0.03$ & $0.51 \pm 0.03$ & 0.20 \\
\hline
\end{tabular}

Table 2: Average, standard error $( \pm)$ and test statistic "t" (P $\leq$ $0.05)$ of the maximum molar bite force $(\mathrm{N})$ of the Rheumatoid Arthritis (RAG) and Control Groups (CG) in the right and left molar regions.

\begin{tabular}{|l|l|l|l|}
\hline Bite Force & RAG & CG & P-value \\
\hline Right Molar & $150.2 \pm 27.2$ & $225.4 \pm 19.2$ & 0.03 \\
\hline Left Molar & $148.8 \pm 33.3$ & $217.41 \pm 22.3$ & 0.10 \\
\hline
\end{tabular}

Table 3: Comparison of mandibular mobility $(\mathrm{cm})$ between the Rheumatoid Arthritis (RAG) and Control Groups (CG) using the "t" test $(\mathrm{P} \leq 0.05)$.

\begin{tabular}{|l|l|l|l|}
\hline Mandibular mobility & RAG & CG & P-value \\
\hline Mouth opening & $36.40 \pm 1.69$ & $41.35 \pm 2.23$ & 0.09 \\
\hline Right lateral excursion & $7.68 \pm 0.92$ & $8.58 \pm 0.69$ & 0.44 \\
\hline Left lateral excursion & $8.72 \pm 1.22$ & $8.34 \pm 0.53$ & 0.78 \\
\hline Protrusion & $6.24 \pm 0.98$ & $6.68 \pm 0.57$ & 0.70 \\
\hline
\end{tabular}

The mandibular mobility data in the condition of maximum mouth opening, right lateral excursion, left lateral excursion and protrusion are shown in Table 3. No significant differences were observed between RAG and $C G(P \geq 0.05)$.

The results of the OHIP-14 questionnaire, comparing RAG and CG are presented in Table 4. Higher scores were observed in RAG vs. CG. This significant difference $(P \leq 0.05)$ was more evident when OHIP-14 issues were grouped in domains characterized by discomfort, pain, limitations, and discomfort $(P \leq 0.01)$.

\section{Discussion}

The stomatognathic system of patients with chronic degenerative diseases presents morphological and functional alterations, compromising the quality of life [15]. Few studies have demonstrated the possible orofacial manifestations resulting from the functional impairment of this complex system in the presence of a rheumatic inflammatory disease $[15,27]$.

Therefore, this study evaluated the impact of rheumatoid arthritis on the stomatognathic system of women who presented an asymptomatic nature of the involvement of the temporomandibular disorder by masseter and temporalis muscles thickness, maximal molar 
Table 4: Average, standard error $( \pm)$ and test statistic "t" $(P \leq 0.05)$ of the OHIP-14 questions and domains for the Rheumatoid Arthritis (RAG) and Control Groups (CG).

\begin{tabular}{|c|c|c|c|}
\hline OHIP & RAG & CG & P-value \\
\hline Difficulty speaking or pronouncing & $1.14 \pm 0.39$ & $0.14 \pm 0.10$ & 0.026 \\
\hline Worsening the palate & $0.86 \pm 0.38$ & $0.07 \pm 0.07$ & 0.050 \\
\hline Pain in the mouth or teeth & $1.93 \pm 0.45$ & $0.29 \pm 0.16$ & 0.003 \\
\hline Difficulty eating some food & $2.21 \pm 0.46$ & $0.50 \pm 0.31$ & 0.005 \\
\hline Feels inhibited & $1.79 \pm 0.43$ & $0.36 \pm 0.20$ & 0.008 \\
\hline Feels tense & $2.00 \pm 0.46$ & $0.50 \pm 0.29$ & 0.011 \\
\hline Dissatisfaction with diet & $1.36 \pm 0.40$ & $0.07 \pm 0.07$ & 0.007 \\
\hline Has interrupted meals & $1.21 \pm 0.37$ & $0.07 \pm 0.07$ & 0.008 \\
\hline Feels difficulty in relaxing & $1.64 \pm 0.39$ & $0.07 \pm 0.07$ & 0.001 \\
\hline Has been embarrassed & $1.93 \pm 0.49$ & $0.29 \pm 0.19$ & 0.006 \\
\hline Has felt angry & $1.93 \pm 0.43$ & $0.07 \pm 0.07$ & 0.001 \\
\hline Have had difficulty doing your daily work & $1.50 \pm 0.45$ & $0.00 \pm 0.00$ & 0.006 \\
\hline Feels that life is less satisfactory & $1.71 \pm 0.47$ & $0.00 \pm 0.00$ & 0.003 \\
\hline Has felt totally incapable of their obligations & $1.07 \pm 0.40$ & $0.00 \pm 0.00$ & 0.019 \\
\hline Functional limitation & $2.00 \pm 0.66$ & $0.21 \pm 0.15$ & 0.014 \\
\hline Physical pain & $4.14 \pm 0.86$ & $0.79 \pm 0.41$ & 0.002 \\
\hline Psychological discomfort & $3.79 \pm 0.87$ & $0.86 \pm 0.47$ & 0.007 \\
\hline Physical limitation & $2.57 \pm 0.65$ & $0.14 \pm 0.14$ & 0.003 \\
\hline Psychological limitation & $3.57 \pm 0.76$ & $0.36 \pm 0.25$ & 0.001 \\
\hline Social restriction & $3.43 \pm 0.82$ & $0.07 \pm 0.07$ & 0.001 \\
\hline Inability & $2.79 \pm 0.73$ & $0.00 \pm 0.00$ & 0.002 \\
\hline OHIP & $22.29 \pm 4.32$ & $2.43 \pm 1.30$ & 0.000 \\
\hline
\end{tabular}

bite force, mandibular mobility and repercussion of the buccal conditions in the quality of life [28], but reporting sensitivity to digital palpation in the pre-auricular region (RDC/TMD). This sensitivity may be related to the deficiency of the local control of proinflammatory cytokines, which contributes to increase the inflammatory process and the sensitivity to mechanical stimuli during rotational and translational movements of the temporomandibular joint [29].

Our results showed that the images of the masseter and temporalis muscles of the women constituting the two groups of this study were well defined, allowing an exact determination of the measures related to the thickness that were shown, without statistical significance for the averages of the studied muscles in the conditions of mandibular rest and dental clenching in maximum voluntary contraction. Therefore, we can report with our results that women with rheumatoid arthritis did not present atrophy or muscular hypertrophy. Data in accordance with Yilmaz, et al. [30] who evaluated the masseter, lateral and medial pterygoid muscles' thickness of twenty-eight patients with rheumatoid arthritis and concluded that there are no changes in the masticatory muscles' thickness when compared to the healthy group.

On the other hand, many patients with rheumatoid arthritis can develop rheumatoid cachexia, a metabolic alteration accompanied by involuntary loss of lean mass, due to the degradation of proteins, mainly of the skeletal striated muscles, provoking increase or stability of the fat mass, without loss of body weight [31-33].

In this study, women with rheumatoid arthritis had the average BMI of $31.1 \pm 1.2 \mathrm{~kg} / \mathrm{m}^{2}$, but because they were in the early stage of the disease, the masticatory muscles' thickness did not have significant morphological changes. Such condition is possibly because the appearance of rheumatoid cachexia, which is a characteristic sign of rheumatoid arthritis in more advanced stages, has not been evidenced.

According to our results, there were significant alterations between the with and without rheumatoid arthritis groups in the maximum molar bite force, with significant statistical difference on the right side. The group with rheumatoid arthritis showed lower molar bite force. Data in accordance with Hoyuela, et al. [15], a study in which women with rheumatoid arthritis and temporomandibular disorder had more signs and symptoms of orofacial pain and lower bite force than women in the healthy control group.

The molar bite force is the result of the interaction of different components of the stomatognathic system that are regulated by the central nervous system $[19,34]$, being considered an important auxiliary method in the diagnosis of alterations in the stomatognathic system, to indicate the functional $[35,36]$.

It is hypothesized that bite force may also be associated with the deficit of local control of proinflammatory cytokines in the joint capsule that covers the temporomandibular joint, causing hemodynamic and pathophysiological instability, with a reduction in functional capacity [29].

International researchers are also concerned with quantifying the jaw movements of the healthy popula- 
tion and with systemic diseases to demonstrate functional changes in the stomatognathic system $[27,37,38]$. Because it is a method of measurement, it is used as a surrogate measurement of the orofacial function due to the difficulty of directly measuring the condyles movements [39].

In the present study, mandibular mobility values at the maximum mouth opening, right lateral excursion, left lateral excursion and protrusion for the group with rheumatoid arthritis reached values very close to the group without the disease. As the women in the rheumatoid arthritis group did not present temporomandibular disorder, the temporomandibular joints probably were not yet in the process of destructive alteration that is evidenced by images, such as joint deformity, periarticular muscle atrophy and rheumatoid nodules, and with this no changes in mandibular mobility pattern occurred. In this study, magnetic resonance imaging or computed tomography was not performed to assess whether there was involvement of the temporomandibular joint and its structural components.

Observing all these variables, we cannot fail to evaluate how the stomatognathic system, more precisely the oral conditions behave in face of the impact on the health and quality of life of the patients. These two terms, health and quality of life, are extremely close, where health contributes to improve the quality of life, being fundamental in the physical and emotional balance of the human being [40].

Many researches use specific questionnaires on quality of life related to oral health to observe the influence of dental problems related to systemic diseases [41,42]. There have been few studies that used the OHIP-14 questionnaire as a methodology for assessing quality of life in individuals with inflammatory arthritis $[43,44]$.

In the present study, we found repercussions of oral conditions on the quality of life of adult women with rheumatoid arthritis with negative impact, observing the total sum of the OHIP-14 questionnaire $(22.29 \pm 4.32)$ when compared to the group without rheumatoid arthritis (2.43 \pm 1.30 ), with significant difference in domains characterized by discomfort, pain, limitations and disability ( $P \leq$ 0.01 ) and in the total score of this evaluation instrument. Data in accordance with Ahola, et al. [41] who reported a higher average OHIP-14 score $(8.80 \pm 11.15)$ in the group with rheumatoid arthritis in relation to the group without the disease $(3.93 \pm 6.60)$, showing that the oral condition is negatively influenced by the rheumatic disease.

Having good quality of life is important, and knowing the factors that alters it becomes a priority in today's world, to seek longevity, associated with health. The evaluation methods of this study show the importance of observing the repercussion of oral conditions on the quality of life, morphology and function of the stomatognathic system of women with rheumatoid arthritis, stating that the alterations are evident, with loss of muscle strength and worsening the quality of life.

As limitations of this study, the absence of evaluation by imaging tests, if there are alterations in the components of the temporomandibular joint due to the influence of chronic inflammation, and if the women presented cachexia, although they were in the initial stage of the disease.

\section{Conclusion}

Adult women with rheumatoid arthritis had a negative impact on the repercussion of oral conditions on quality of life characterized by discomfort, pain, limitations and functional disability, as well as reduction in maximum molar bite force, without compromising the masseter and temporalis muscles' thickness and mandibular mobility.

\section{Ethical statement}

All individuals were required and signed the informed consent form to participate in this research. The ethical approval for the study protocol was obtained by the Research Ethics Committee of the Faculty of Dentistry of the University of São Paulo, Brazil.

\section{References}

1. Ji J, Zhang L, Zhang Q, Yin R, Fu T, et al. (2017) Functional disability associated with disease and quality-of-life parameters in Chinese patients with rheumatoid arthritis. Health Qual Life Outcomes 15: 89.

2. Rosa-Gonçalves D, Bernardes M, Costa L (2017) Quality of life and functional capacity in patients with rheumatoid arthritis - Cross-sectional study. Reumatol Clin.

3. Bugatti S, Bogliolo L, Montecucco C, Manzo A (2016) B cell autoimmunity and bone damage in rheumatoid arthritis. Reumatismo 68: 117-125.

4. Derksen VFAM, Huizinga TWJ, van der Woude D (2017) The role of autoantibodies in the pathophysiology of rheumatoid arthritis. Semin Immunopathol 39: 437-446.

5. da Mota LM, Cruz BA, Brenol CV, Pereira IA, Fronza LS, et al. (2011) 2011 Consensus of the Brazilian Society of Rheumatology for diagnosis and early assessment of rheumatoid arthritis. Rev Bras Reumatol 51: 199-219.

6. Twigg S, Hensor EMA, Freeston J, Tan AL, Emery P, et al. (2017) Fatigue, older age, higher body mass index and female gender predict worse disability in early rheumatoid arthritis despite treatment to target: A comparison of two observational cohort studies from the United Kingdom. Arthritis Care Res (Hoboken).

7. Katz $P$ (2017) Fatigue in rheumatoid arthritis. Curr Rheumatol Rep 19: 25.

8. Pedersen TK, Jensen JJ, Melsen B, Herlin T (2001) Resorption of the temporomandibular condylar bone according to subtypes of juvenile chronic arthritis. J Rheumatol 28: 2109-2115.

9. Andrade KM, Alfenas BF, Campos $\mathrm{CH}$, Rodrigues Garcia RC (2017) Mandibular movements in older people with rheumatoid arthritis. Oral Surg Oral Med Oral Pathol Oral Radiol 123: e153-e159.

10. Myasoedova E, Crowson CS, Kremers HM, Therneau TM, Gabriel SE (2010) Is the incidence of rheumatoid arthritis rising?: results from Olmsted County, Minnesota, 19552007. Arthritis Rheum 62: 1576-1582.

11. Berner C, Erlacher L, Quittan M, Fenzl KH, Dorner TE 
(2017) Workability and muscle strength in patients with seropositive rheumatoid arthritis: survey study protocol. JMIR Res Protoc 6: e36.

12. Hunter TM, Boytsov NN, Zhang X, Schroeder K, Michaud K, et al. (2017) Prevalence of rheumatoid arthritis in the United States adult population in healthcare claims databases, 2004-2014. Rheumatol Int.

13. Lawrence RC, Helmick CG, Arnett FC, Deyo RA, Felson DT, et al. (1998) Estimates of the prevalence of arthritis and selected musculoskeletal disorders in the United States. Arthritis Rheum 41: 778-799.

14. da Cunha DV, Degan VV, Vedovello Filho M, Bellomo DP Jr, Silva MR, et al. (2017) Real-time three-dimensional jaw tracking in temporomandibular disorders. J Oral Rehabil 44: 580-588.

15. Hoyuela CP, Furtado RN, Chiari A, Natour J (2015) Oro-facial evaluation of women with rheumatoid arthritis. J Oral Rehabil 42: 370-377.

16. Resnick CM, Vakilian PM, Kaban LB, Peacock ZS (2016) Quantifying the effect of temporomandibular joint intra-articular steroid injection on synovial enhancement in juvenile idiopathic arthritis. J Oral Maxillofac Surg 74: 2363-2369.

17. Hirahara N, Kaneda T, Muraoka H, Fukuda T, Ito K, et al. (2017) Characteristic magnetic resonance imaging findings in rheumatoid arthritis of the temporomandibular joint: focus on abnormal bone marrow signal of the mandibular condyle, pannus, and lymph node swelling in the parotid glands. J Oral Maxillofac Surg 75: 735-741.

18. Fernandes Azevedo AB, Câmara-Souza MB, Dantas IS, de Resende CMBM, Barbosa GAS (2017) Relationship between anxiety and temporomandibular disorders in dental students. Cranio 9: 1-4.

19. Palinkas M, Nassar MS, Cecílio FA, Siéssere S, Semprini $M$, et al. (2010) Age and gender influence on maximal bite force and masticatory muscles thickness. Arch Oral Biol 55: 797-802.

20. Castelo PM, Gavião MB, Pereira LJ, Bonjardim LR (2007) Masticatory muscle thickness, bite force, and occlusal contacts in young children with unilateral posterior crossbite. Eur J Orthod 29: 149-156.

21. Regalo SC, Santos CM, Vitti M, Regalo CA, de Vasconcelos PB, et al. (2008) Evaluation of molar and incisor bite force in indigenous compared with white population in Brazil. Arch Oral Biol 53: 282-286.

22. Bonjardim LR, Lopes-Filho RJ, Amado G, Albuquerque RL Jr, Goncalves SR (2009) Association between symptoms of temporomandibular disorders and gender, morphological occlusion, and psychological factors in a group of university students. Indian J Dent Res 20: 190-194.

23. Spagnol G, Palinkas M, Regalo SC, de Vasconcelos PB, Sverzut CE, et al. (2016) Impact of midface and upper face fracture on bite force, mandibular mobility, and electromyographic activity. Int J Oral Maxillofac Surg 45: 1424-1429.

24. Oliveira BH, Nadanovsky P (2005) Psychometric properties of the Brazilian version of the Oral Health Impact Profile-short form. Community Dent Oral Epidemiol 33: 307-314.

25. Borges Tde F, Regalo SC, Taba M Jr, Siéssere S, Mestriner W Jr, et al. (2013) Changes in masticatory performance and quality of life in individuals with chronic periodontitis. $J$ Periodontol 84: 325-331.

26. Campos JADB, Zucoloto ML, Bonafé FSS, Maroco J (2017) General oral health assessment index: A new evaluation proposal. Gerodontology 34: 334-342.

27. Tegelberg A, Kopp S (1987) Clinical findings in the stomatognathic system for individuals with rheumatoid arthritis and osteoarthrosis. Acta Odontol Scand 45: 65-75.
28. Cordeiro PC, Guimaraes JP, de Souza VA, Dias IM, Silva $\mathrm{JN}$, et al. (2016) Temporomandibular joint involvement in rheumatoid arthritis patients: association between clinical and tomographic data. Acta Odontol Latinoam 29: 123-129.

29. Ahmed N, Catrina Al, Alyamani AO, Mustafa H, Alstergren P (2015) Deficient cytokine control modulates temporomandibular joint pain in rheumatoid arthritis. Eur $\mathrm{J}$ Oral Sci 123: 235-241.

30. Yilmaz HH, Yildirim D, Ugan Y, Tunc SE, Yesildag A, et al. (2012) Clinical and magnetic resonance imaging findings of the temporomandibular joint and masticatory muscles in patients with rheumatoid arthritis. Rheumatol Int 32: 11711178.

31. Roubenoff R, Roubenoff RA, Cannon JG, Kehayias JJ, Zhuang $\mathrm{H}$, et al. (1994) Rheumatoid cachexia: cytokine-driven hypermetabolism accompanying reduced body cell mass in chronic inflammation. J Clin Invest 93: 2379-2386.

32. Fukuda W, Omoto A, Oku S, Tanaka T, Tsubouchi Y, et al. (2010) Contribution of rheumatoid arthritis disease activity and disability to rheumatoid cachexia. Mod Rheumatol 20: 439-443.

33. Okano T, Inui K, Tada M, Sugioka $\mathrm{Y}$, Mamoto $\mathrm{K}$, et al. (2017) Loss of lean body mass affects low bone mineral density in patients with rheumatoid arthritis - results from the Tomorrow study. Mod Rheumatol 7: 1-7.

34. Ow RK, Carlsson GE, Jemt T (1989) Biting forces in patients with craniomandibular disorders. Cranio 7: 119-125.

35. Koc D, Dogan A, Bek B (2010) Bite force and influential factors on bite force measurements: a literature review. Eur J Dent 4: 223-232.

36. Awawdeh L, Hemaidat K, Al-Omari W (2017) Higher maximal occlusal bite force in Endodontically Treated Teeth Versus Vital Contralateral Counterparts. J Endod 43: 871-887.

37. Cunha CO, Pinto LM, de Mendonça LM, Saldanha $A D$, Conti AC, et al. (2012) Bilateral asymptomatic fibrous-ankylosis of the temporomandibular joint associated with rheumatoid arthritis: a case report. Braz Dent J 23: 779-782.

38. Matarese G, Isola G, Alibrandi A, Lo Gullo A, Bagnato G, et al. (2016) Occlusal and MRI characterizations in systemic sclerosis patients: A prospective study from Southern Italian cohort. Joint Bone Spine 83: 57-62.

39. Buschang PH, Throckmorton GS, Travers KH, Hayasaki $H$ (2001) Incisor and mandibular condylar movements of young adult females during maximum protrusion and lateratrusion of the jaw. Arch Oral Biol 46: 39-48.

40. Karaman A, Yuksel I, Kinikli GI, Caglar O (2017) Do Pilates-based exercises following total knee arthroplasty improve postural control and quality of life? Physiother Theory Pract 33: 289-295.

41. Ahola K, Saarinen A, Kuuliala A, Leirisalo-Repo M, Murtomaa $\mathrm{H}$, et al. (2015) Impact of rheumatic diseases on oral health and quality of life. Oral Dis 21: 342-348.

42. Heidari E, Andiappan M, Banerjee A, Newton JT (2017) The oral health of individuals with dental phobia: a multivariate analysis of the Adult Dental Health Survey, 2009. Br Dent J 222: 595-604.

43. Stewart CM, Berg KM, Cha S, Reeves WH (2008) Salivary dysfunction and quality of life in Sjögren syndrome: a critical oral-systemic connection. J Am Dent Assoc 139: 291-299.

44. Azuma N, Katada Y, Kitano S, Sekiguchi M, Kitano M, et al. (2014) Correlation between salivary epidermal growth factor levels and refractory intraoral manifestations in patients with Sjögren's syndrome. Mod Rheumatol 24: 626-632. 